\title{
Identification of volatile flavor compounds in Jeju citrus fruits
}

\author{
Young Shin Hong, Kyong Su Kim* \\ Department of Food and Nutrition, Chosun University, Gwangju 61452, Korea
}

\section{제주감귤류의 휘발성 향기성분의 확인}

\author{
홍영신 · 김경수 * \\ 조선대학교 식품영양학과
}

\begin{abstract}
The volatile flavor compounds in five Jeju citrus fruit varieties (Cheonhyehyang, Hallabong, Jinjihyang, Hwanggeum hyang and Redhyang) were extracted by simultaneous distillation-extraction (SDE) using solvent mixture of $n$-pentane and diethyl ether (1:1, v/v) and analyzed by using gas chromatography-mass spectrometry (GC-MS). The number of aroma compounds were identified with : $104(4,939.77 \mathrm{mg} / \mathrm{kg})$ in Cheonhyehyang, $98(3,286.38 \mathrm{mg} / \mathrm{kg})$ in Hallabong, $105(3,317.56 \mathrm{mg} / \mathrm{kg})$ in Jinjihyang, $102(4,293.39 \mathrm{mg} / \mathrm{kg})$ in Hwanggeumhyang, and $108(4,049.94 \mathrm{mg} / \mathrm{kg})$ in Redhyang. The detected main volatile compounds were; limonene, sabinene, $\beta$-myrcene, $\alpha$-pinene, $\beta$-pinene, linalool, 4-terpineol, $a$-terpineol, (E)- $\beta$-ocimene and $\gamma$-terpinene. Among the identified volatiles compounds, ethyl-benzene, nonanol, 1-p-menthen-9-al, (E)-isocarveol, methyl salicylate, a-terpinen-7-al, perilla alcohol, and ethyl-dodecanoate were detected in Cheonhyehyang. only Furthermore, $\beta$-chamigrene and $\alpha$-selinene were in Hallabong only; 3-hydroxybutanal, (E)-2-nonenal, isobomeol, octyl acetate, (E)-2-undecenal, $\beta$-ylangene and guaia-6,9-diene in Jinjihyang. $\rho$-Cymenene, $\beta$-thujone, selina-4,11-diene and (E,E)-2,6-famesol in Hwanggeumhyang only; and $\rho$-cymen-8-0l, bornyl acetate, carvacrol, bicycloelemene, a-cubebene and 7-epi- $a$-selinene in Redhyang only. This study confirmed the differences in composition and content of volatile aroma components in five varieties of Jeju citrus fruits.
\end{abstract}

Key words : volatile flavor compounds, Jeju citrus fruits, SDE, GC/MS

\section{서 론}

우리나라에서 주로 생산되고 있는 citrus속 과일은 mandarin(Citrus reticulata L.)으로 제주도에서 재배되고 있 는 온주밀감이다. 이는 쉽게 껍질이 제거되고 밝은 색깔을 가지고 있으며, 상쾌한 감귤 향기와 새콤달콤한 맛을 가지 고 있어 신선한 과일로 소비되는 가장 인기 있는 감귤이다 $(1,2)$. 제주 감귤류는 1960 년 대부터 본격적으로 재배되기 시작하면서 농가소득의 증대를 가져왔으며, 1970년 이후 경제가 발전하면서 소비의 확대로 재배면적이 늘어나 생산

*Corresponding author. E-mail : kskim@chosun.ac.kr Phone : 82-62-230-7724, Fax: 82-62-224-8880

Received 13 October 2016; Revised 1 December 2016; Accepted 11 December 2016.

Copyright (c) The Korean Society of Food Preservation. All rights reserved.
량이 증가하였다(3). 1995년 우리나라가 WTO(world trade organization)에 가입을 시작으로 FTA(free trade agreement)의 적 용범위도 확대되어 오렌지의 수입이 증가하게 되었다. 이 에 따라 제주에서 생산되고 있는 온주밀감(satsuma mandarin)의 경쟁력이 감소할 수밖에 없었다. 수입과일에 대한 경쟁력을 높이며, 감귤류의 안정적인 공급을 위하여 신품종인 여러 종류의 만감류가 개발되었다. 온주밀감은 11 12월에 수확을 하며, 만감류는 나무에서 완전히 익혀 늦게 수확하는 품종이다. 대표적으로 한라봉, 천혜향이 주 로 재배되고 있으며, 진지향, 황금향, 레드향, 청견 및 네블 오렌지 등이 있다(4). 온주밀감과 비교하였을 때 만감류의 조수입이 높으며, 한라봉, 천혜향 및 진지향 등은 소비자의 선호도가 높다. 감귤재배의 전체면적은 줄어들고 있는데 만감류의 재배면적은 1990년 385 ha에서 2012년 1,870 ha로 확대되어 생산량이 약 11 배 이상 증가하였다(5). 한라봉은 청견과 온주밀감류를 교접하였으며, 천혜향은 오렌지와 귤 
을 교접한 품종으로 당도가 높고 향이 좋다. 진지향은 청견 과 흥진 조생감귤을 교접한 신품종으로 모양은 귤과 유사하 지만 감귤과는 전혀 다른 맛이 나며, 황금향은 한라봉과 천혜향을 교접한 품종으로 신맛이 적고 당도가 높다. 레드 향은 한라봉과 온주밀감류인 서지향을 교접하여 만든 신품 종으로 껍질이 얇고 과즙이 많은 만감류이다.

향미는 분자량이 300 미만인 화합물로 코의 상부 후각 시스템으로 이송될 정도로 충분한 휘발성을 가지는 화합물 로 냄새 및 향의 특성을 가진다. 식품속의 향미는 냄새를 만드는 향기 물질과 맛을 내는 화합물로 구분되어진다. 일 반적으로 식품에 존재하는 휘발성 화합물은 다양한 구성 요소를 포함하고 있지만, 향미 물질은 매우 적은 양으로 존재한다. 열 공정에 의해 만들어지는 커피 및 발효과정을 거치는 빵, 맥주, 코코아, 차 등은 800 개 이상의 휘발성 화합 물이 함유되어 있지만 제한된 수만이 향미로서 중요한 특성 을 가진다. 향미 화합물은 식품 서비스 산업에서 다양한 상품들의 품질 증가를 위하여 사용되고 있는 향료의 제조 과정에서 매우 중요한 역할을 한다(6,7). 냄새를 인식할 수 있는 최저 농도를 냄새의 역가 또는 인식의 역가라고 하며, 식품들의 관능검사에 의해서 결정된다. 향미 물질들은 냄 새 및 인식의 역가보다 더 높은 농도로 식품 속에 존재하고 있다(8). Mandarin 품종 주스의 휘발성 성분의 조성은 오렌 지 주스의 휘발성 성분과 비슷하지만 휘발성 화합물의 수와 함량은 분석기술과 시료준비 절차에 따라 다른 결과가 보고 되고 있다(9-11). Mandarin 과피 오일의 향기 특성은 dimethyl anthranilate, thymol, a-terpinene 및 $\beta$-pinene의 조 합에 의한 것이라고 보고되었다(12). 이와 같이 mandarin의 휘발성 향기성분에 대한 연구는 많이 보고되고 있으나, 수 입과일에 대해 경쟁력을 높이기 위해서 개발된 신품종인 만감류(천혜향, 한라봉, 진지향, 황금향 및 레드향)의 휘발 성 향기성분에 대한 연구는 미흡한 실정이다. 본 연구는 제주 감귤류인 만감류 과피의 휘발성 향기성분에 대해 분석 하였다. 향기성분 분석을 위하여 $\mathrm{SDE}$ (simultaneous distillation extraction) 방법으로 휘발성 유기화합물을 추출 하여 GC/MS로 확인하였다. 이에 따라 국내 신품종인 만감 류 과피의 품종별 휘발성 향기성분의 특성과 차이점을 구분 하며, 상업적으로 이용되고 있는 citrus속 과일의 정유성분 에 대한 기초연구자료를 제공하고자 수행하였다.

\section{재료 및 방법}

\section{재 료}

Citrus속 과일의 휘발성 향기성분을 분석하기 위하여 제 주 감귤류인 천혜향(Citrus hybrid 'Setoka), 한라봉(C. hybrid 'Shiranui'), 진지향(C. hybrid 'Tsunokaori), 황금향 (C. hybrid 'Blanco) 및 레드향(C. hybrid 'Kanpei)을 2014년
12 월에 광주지역 재래시장 및 마트에서 직접 구입하였다. 본 실험에 사용한 시료들은 생과일 상태에서 불순물을 제거 하고 증류수로 세척한 후 $-70^{\circ} \mathrm{C}$ 의 deep freezer(MDFU4086S, Sanyo, Tokyo, Japan)에 보관한 후 과피만을 분리 하여 시료로 사용하였다.

\section{시 약}

본 연구에 사용한 모든 시약은 특급시약으로 Sigma사(St. Louis, MO, USA)와 Fisher Scientific(Waltham, Waltham, MA, USA)로부터 구입하였다. 휘발성 유기성분 추출을 위하여 diethyl ether, n-pentane 등의 유기용매는 HPLC grade로 구 입하여, 이를 다시 wire spiral packed double distilling appratus(Normschliff Geratebau, Wertheim, Baden-Wurttemberg, Germany) 장치로 재증류한 것을 사용하였다. 물은 순수재증 류장치(Millpore corporation, Bedford, MA, USA)에서 얻은 탈이 온수(ultra pure water)를 사용하였다. 유기용매의 탈수에 사용된 무수 $\mathrm{Na}_{2} \mathrm{SO}_{4}$ 는 $650^{\circ} \mathrm{C}$ 회화로에서 하룻저녁 태운 뒤 desiccator에 서 방냉한 후 유기용매의 탈수에 사용하였다.

\section{휘발성 유기화합물의 추출}

제주감귤류의 과피 $(40 \mathrm{~g})$ 를 ultra turrax로 분쇄하여 탈이 온수 $500 \mathrm{~mL}$ 를 혼합하여 $1 \mathrm{~N} \mathrm{NaOH}$ 용액으로 $\mathrm{pH}$ 7.0으로 조정한 후 이를 휘발성 향기성분의 추출용 시료로 사용하였 다. 휘발성 향기성분의 추출을 위하여 Schultz 등(13)의 방 법에 따라 개량된 연속수증기증류추출장치(Likens \& Nickerson type simultaneous distillation \& extraction apparatus, SDE, Normschliff, Wertheim, Baden-Wurttemberg, Germany)(14) 에서 n-pentane:diethylether 혼합용매(1:1, v/v) $100 \mathrm{~mL}$ 를 사 용하여 상압하에서 3 시간 동안 추출하였다. 정량분석을 위 해 n-butylbenzene $1 \mu \mathrm{L}$ 를 내부표준물질로 추출용 시료에 첨가하였다. 추출된 휘발성 향기성분의 유기용매 분획분은 Vigreux column $(250 \mathrm{~mL}$, Normschliff Geratebau)을 이용하 여 약 $3 \mathrm{~mL}$ 까지 농축한 후 $\mathrm{GC}$ 용 vial에 옮겨 질소가스를 이용하여 약 $1 \mathrm{~mL}$ 까지 농축하여 $\mathrm{GC} / \mathrm{MS}$ 의 분석시료로 사 용하였다.

\section{휘발성 유기화합물 분석}

$\mathrm{SDE}$ 방법을 이용하여 추출한 후 농축된 휘발성 향기성분 을 GC/MS(gas chromatography/mass spectrometry)로 분석 하였다. 분석에 사용한 $\mathrm{GC} / \mathrm{MS}$ 는 GCMS-QP2010Plus (Shimadzu, Kyoto, Japan) 기기를 사용하였다. 분리된 휘발 성 향기성분의 이온화는 EI(electron impact ionization)방법 으로 행하였다. GC/MS 분석조건은 ionization voltage를 70 $\mathrm{eV}$ 로 하였으며, injector의 온도는 $250^{\circ} \mathrm{C}$ 로 하였다. 분석할 분자량의 범위는 40 350(m/z)으로 설정하였으며, Column 은 DB-5(60 $\mathrm{m} \times 0.25 \mathrm{~mm}$ i.d., $0.25 \mu \mathrm{m}$ film thickness, J\&W, Santa Clara, CA, USA)를 사용하였고, 온도 프로그램은 $40^{\circ} \mathrm{C}$ 
에서 3 분간 유지한 다음 $2^{\circ} \mathrm{C} / \mathrm{min}$ 의 속도로 $150^{\circ} \mathrm{C}$ 까지 상승 시켜 5 분간 유지하고, 동일한 속도로 $180^{\circ} \mathrm{C}$ 까지 승온시켜 5 분간 유지하였다. 다시 $4^{\circ} \mathrm{C} / \mathrm{min}$ 의 속도로 $200^{\circ} \mathrm{C}$ 까지 상승 시킨 후 10 분간 유지한 다음 $5^{\circ} \mathrm{C} / \mathrm{min}$ 의 속도로 $230^{\circ} \mathrm{C}$ 까지 상승시킨 후 10 분간 유지하도록 설정하였다. Carrier gas는 helium을 사용하여 유속은 $1.0 \mathrm{~mL} / \mathrm{min}$ 으로 하였으며, 휘발 성 향기성분은 $1 \mu \mathrm{L}$ 를 split ratio 1:30로 주입하였다.

\section{휘발성 향기성분의 확인 및 정량}

$\mathrm{GC} / \mathrm{MS}$ 에 의해 $\mathrm{TIC}$ (total ionization chromatogram)에 분 리된 각 peak의 성분 분석은 mass spectrum library(NIST 05, WILEY 7 과 FFNSC 2)와 mass spectral data book의 spectrum(15,16)과의 일치 및 GC/MS 분석에 의한 retention index와 문헌상의 retention index $(17,18)$ 와의 일치 및 표준 물질의 분석 data를 비교하여 확인하였다. 동정된 휘발성 향기성분의 상대적 정량을 위하여 내부표준물질로 첨가된 $n$-butyl benzene과 각 휘발성 화합물의 peak area\% 비교하여 각 휘발성 화합물의 함유량을 계산하였다.

\section{결과 및 고찰}

\section{천혜향의 휘발성 향기성분}

천혜향의 휘발성 향기성분을 $\mathrm{SDE}$ 방법으로 추출하여 $\mathrm{GC} / \mathrm{MS}$ 로 확인한 화합물들의 chromatogram을 Fig. 1에 도 식하였고, area\% 및 함량을 Table 1에 나타내었다. 천혜향에 서 확인된 휘발성 화합물은 104 종으로 함량은 4939.77 $\mathrm{mg} / \mathrm{kg}$ 으로 확인되었다. 천혜향의 휘발성 화합물은 관능기 별로는 aldehyde류와 hydrocarbon류가 각각 25종으로 동정 되었고, 그 다음으로 alcohol류 24종, ester류 15종, acid류 6종, ketone류 5종 및 oxide류 4종 순으로 확인되었다. 관능 기별 상대적 peak area는 hydrocarbon류가 $61.04 \%$ 로 가장 높았으며, alcohol류가 $18.94 \%$, aldehyde류 $11.55 \%$, oxide류 $2.70 \%$, ester류 $2.46 \%$, acid류 $2.35 \%$ 및 ketone류 $0.94 \%$ 순으 로 정량되었다(Table 2). 천혜향 과피에서 limonene이 $42.57 \%$ 로 가장 높은 peak area을 보였으며, 함량은 2,102.93 $\mathrm{mg} / \mathrm{kg}$ 으로 동정되었다. Limonene $\left(\mathrm{C}_{10} \mathrm{H}_{16}\right)$ 은 단환식 mono terpene hydrocarbon류로 2개의 이소프렌 단위로 구성되어 있고, 상쾌한 향이 특징이다. 또한 감귤 특유의 향기성분으 로 항암효과와 중추신경 흥분을 진정시킨다고 알려져 있으 며, 인체에 무독하여 비누, 향수, 방향제 등의 화장품과 여러 가지 식품에 사용되고 있다 $(19,20)$. 천혜향의 휘발성 향기 성분은 limonene 이외에 sabinene $6.61 \%(326.45 \mathrm{mg} / \mathrm{kg})$, linalool $5.17 \%(255.24 \mathrm{mg} / \mathrm{kg})$, decanal $3.73 \%(184.32 \mathrm{mg} / \mathrm{kg})$, limonene-10-ol $3.01 \%(148.88 \mathrm{mg} / \mathrm{kg})$, 4-terpineol $2.65 \%$ $(130.67 \mathrm{mg} / \mathrm{kg}), \beta$-myrcene $2.58 \%(127.57 \mathrm{mg} / \mathrm{kg}), \beta$-pinene $2.32 \%(114.62 \mathrm{mg} / \mathrm{kg})$ 등 순으로 분석되었다. 강(21)의 연구
에서는 미숙과 천혜향 에센셜 오일에 linalool과 4-terpineol 및 sabinene의 함량을 각각 $7.21,6.47$ 및 2.99\%로 보고하였 는데 본 연구에서는 sabinene의 함량이 더 높게 확인되었다. 천혜향에서는 67종의 terpenoid류가 확인되었으며, 전체 향 기성분의 $86.19 \%$ 로 $4,257.41 \mathrm{mg} / \mathrm{kg}$ 이 함유된 것으로 나타 났다. 이중 monoterpene hydrocarbon류가 59.36\%(2,932.01 $\mathrm{mg} / \mathrm{kg}$ )로 가장 많았으며, 다음으로 oxy genated monoterpene 류가 $24.28 \%(1,199.60 \mathrm{mg} / \mathrm{kg})$ 를 차지하였다(Table 3). 천혜 향에 함유되어 있는 monoterpene hydrocarbon류 중 주요 향기성분으로는 limonene 이 외에 sabinene, $\beta$-myrcene, $\beta$ -pinene, a-pinene, (E)- $\beta$-ocimene, $\gamma$-terpinene 및 $a$ -terpinolene 순으로 확인되었다. Sabinene은 달콤한 향이 특징으로 향기의 강도가 높게 평가되고 있으며, (E)- $\beta$ -ocimene은 꽃향기 및 달콤한 향을 나타내는 것으로 보고되 고 있다(22). $\beta$-Myrcene은 향긋한 향으로 sweet-balsamicherbaceous한 특성을 가지고 있다고 보고되었다(23). Sesqui terpene hydrocarbon류는 $\beta$-elemene의 함량이 가장 높았으 며, 그 외에 (E)- $\beta$-farnesene, (E,E)- $a$-farnesene, valencene, sesquisabinene, a-humulene, $\delta$-cadinene, 및 $\beta$-sesqui phellandrene 등 순으로 확인되었다. $\beta$-Elemene은 종양 세포 성장을 억제하는 천연 항암제로 작용하며, 산화적 손상에 대해 세포를 보호하는 항산화 활성이 있다고 알려져 있다 $(24,25)$. Oxygenated monoterpene류 중 가장 많은 함량을 나타낸 향기성분은 floral과 lemon-like한 특성을 가지는 linalool 이었으며, 그 밖의 다른 화합물로는 limonen-10-ol, 4-terpineol, (E)-carveol, (E)-limonene oxide, a-terpineol, (E)$\beta$-terpineol, (Z)-carveol, (Z)-limonene oxide, carvone, citronellal, perilla alcohol, citronellol, geranial 및 geraniol 등 순으로 확인되었다. 4-Terpineol은 그램 음성과 양성 박 테리아에 대해 항균활성을 나타내며, 흑색종 세포의 성장 을 억제하고 고혈압의 완화 및 체내 염증 유발인자의 생성 을 억제하는 등 약리적 효과를 가진다고 보고되었다 (26-28). Oxygenated sesquiterpene류는 $\beta$-sinensal, $a$-sinensal, spathulenol, nootkatone, caryophyllene oxide, (E)-nerolidol, humulene epoxide II, neo-intermedeol 및 T-muurolol 등 순으 로 분석되었다. 천혜향에서 분석된 aliphatic 화합물은 butanone, ethyl acetate, (E)-2-heptene, (E)-2-hexenal, (Z)3-hexen-1-ol, ethyl benzene 및 methyl salicylate 등이 확인되 었다. Ethyl benzene, nonanol, 1-p-men then-9-al, (E)isocarveol, methyl salicylate, a-terpinen-7-al, perilla alcohol 및 ethyl dodecanoate은 천혜향에서만 확인된 휘발성 향기 성분이다.

\section{한라봉의 휘발성 향기성분}

한라봉의 과피를 분리하여 $\mathrm{SDE}$ 방법으로 휘발성 향기성 분을 추출한 후 $\mathrm{GC} / \mathrm{MS}$ 로 확인하였다. 이들 화합물의 chromatogram은 Fig. 1에 도식하였으며, 상대적 농도를 

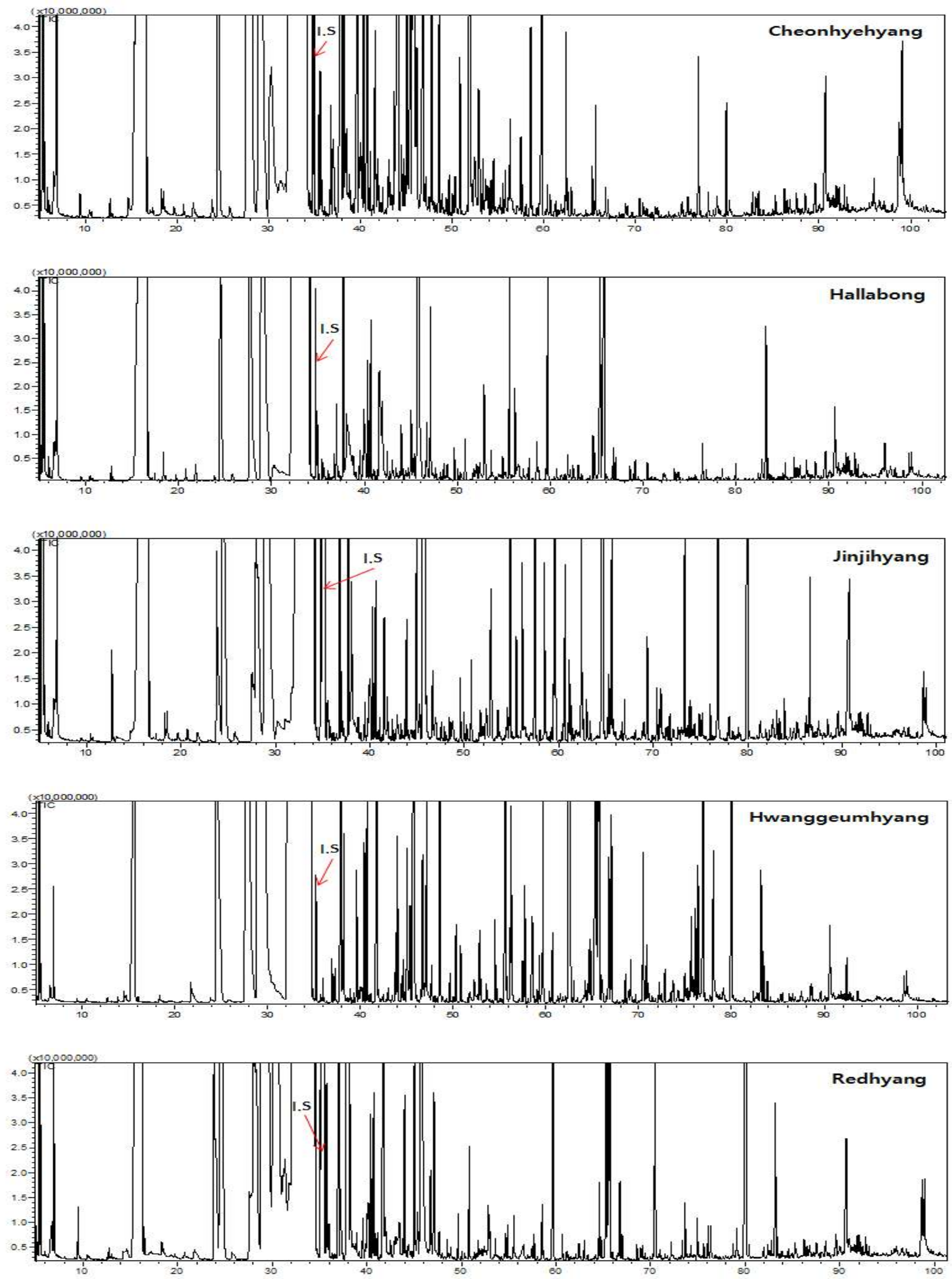

Fig. 1. GC/MS Chromatograms of the volatile flavor compounds in Jeju citrus fruits. 
Table 1. Volatile flavor compounds identified in Jeju citrus fruits

\begin{tabular}{|c|c|c|c|c|c|c|c|c|c|c|c|c|c|}
\hline \multirow{2}{*}{ No } & \multirow{2}{*}{$\mathrm{RI}^{1)}$} & \multirow{2}{*}{ Compound Name } & \multirow{2}{*}{$\mathrm{MF}^{2)}$} & \multicolumn{2}{|c|}{ Cheonhyehyang } & \multicolumn{2}{|c|}{ Hallabong } & \multicolumn{2}{|c|}{ Jinjihyang } & \multicolumn{2}{|c|}{ Hwanggeumhyang } & \multicolumn{2}{|c|}{ Redhyang } \\
\hline & & & & area\% & $\mathrm{mg} / \mathrm{kg}$ & area\% & $\mathrm{mg} / \mathrm{kg}$ & area\% & $\mathrm{mg} / \mathrm{kg}$ & area\% & $\mathrm{mg} / \mathrm{kg}$ & area $\%$ & $\mathrm{mg} / \mathrm{kg}$ \\
\hline 1 & 560 & Butanone & $\mathrm{C}_{4} \mathrm{H}_{8} \mathrm{O}$ & 0.15 & 7.27 & 0.20 & 6.67 & 0.15 & 5.04 & - & - & - & - \\
\hline 2 & 574 & 3-Hydroxybutanal & $\mathrm{C}_{4} \mathrm{H}_{8} \mathrm{O}_{2}$ & - & - & - & - & 0.97 & 32.12 & - & - & - & - \\
\hline 3 & 575 & Ethyl acetate & $\mathrm{C}_{4} \mathrm{H}_{8} \mathrm{O}_{2}$ & 0.86 & 42.45 & 1.26 & 41.53 & - & - & 0.22 & 9.49 & 0.44 & 17.94 \\
\hline 4 & 631 & 3-Methyl butanal & $\mathrm{C}_{5} \mathrm{H}_{10} \mathrm{O}$ & - & - & - & - & - & - & - & - & 0.00 & 0.09 \\
\hline 5 & 697 & 2-Pentanol & $\mathrm{C}_{5} \mathrm{H}_{12} \mathrm{O}$ & 0.05 & 2.26 & 0.01 & 0.39 & 0.01 & 0.20 & 0.01 & 0.32 & 0.08 & 3.27 \\
\hline 6 & 705 & (E)-2-Heptene & $\mathrm{C}_{7} \mathrm{H}_{14}$ & 0.00 & 0.12 & - & - & - & - & - & - & 0.00 & 0.14 \\
\hline 7 & 707 & Acetoin & $\mathrm{C}_{4} \mathrm{H}_{8} \mathrm{O}_{2}$ & 0.00 & 0.16 & 0.01 & 0.24 & 0.00 & 0.12 & - & - & - & - \\
\hline 8 & 771 & 3-Methyl-2-buten-1-ol & $\mathrm{C}_{5} \mathrm{H}_{10} \mathrm{O}$ & - & - & - & - & 0.01 & 0.47 & 0.00 & 0.15 & 0.00 & 0.19 \\
\hline 9 & 792 & 2,3-Butanediol & $\mathrm{C}_{4} \mathrm{H}_{10} \mathrm{O}_{2}$ & - & - & - & - & - & - & 0.04 & 1.52 & 0.02 & 0.84 \\
\hline 10 & 799 & Hexanal & $\mathrm{C}_{6} \mathrm{H}_{12} \mathrm{O}$ & 0.10 & 4.91 & 0.01 & 0.25 & 0.04 & 1.31 & 0.02 & 1.07 & 0.05 & 2.00 \\
\hline 11 & 854 & (E)-2-Hexenal & $\mathrm{C}_{6} \mathrm{H}_{10} \mathrm{O}$ & 0.06 & 3.14 & 0.12 & 4.03 & 0.11 & 3.74 & 0.03 & 1.13 & 0.02 & 1.01 \\
\hline 12 & 856 & (Z)-3-Hexen-1-ol & $\mathrm{C}_{6} \mathrm{H}_{12} \mathrm{O}$ & 0.01 & 0.73 & 0.02 & 0.71 & - & - & - & - & - & - \\
\hline 13 & 859 & Ethyl-benzene & $\mathrm{C}_{8} \mathrm{H}_{10}$ & 0.01 & 0.72 & - & - & - & - & - & - & - & - \\
\hline 14 & 900 & Heptanal & $\mathrm{C}_{7} \mathrm{H}_{14} \mathrm{O}$ & 0.02 & 1.18 & 0.10 & 3.33 & 0.06 & 1.97 & 0.12 & 5.32 & 0.07 & 2.93 \\
\hline 15 & 925 & a-Thujene & $\mathrm{C}_{10} \mathrm{H}_{16}$ & 0.08 & 3.91 & 0.04 & 1.39 & 1.06 & 35.02 & 0.01 & 0.59 & 1.23 & 49.98 \\
\hline 16 & 933 & a-Pinene & $\mathrm{C}_{10} \mathrm{H}_{16}$ & 2.30 & 113.68 & 2.49 & 81.68 & 3.70 & 122.79 & 3.04 & 130.35 & 4.23 & 171.34 \\
\hline 17 & 949 & Camphene & $\mathrm{C}_{10} \mathrm{H}_{16}$ & 0.06 & 2.88 & 0.07 & 2.31 & 0.07 & 2.20 & 0.00 & 0.20 & 0.05 & 2.02 \\
\hline 18 & 972 & Sabinene & $\mathrm{C}_{10} \mathrm{H}_{16}$ & 6.61 & 326.45 & 4.06 & 133.59 & 0.57 & 18.92 & 1.44 & 61.85 & 0.44 & 17.74 \\
\hline 19 & 977 & $\beta$-Pinene & $\mathrm{C}_{10} \mathrm{H}_{16}$ & 2.32 & 114.62 & 1.92 & 63.18 & 2.22 & 73.61 & 3.52 & 150.99 & 2.48 & 100.55 \\
\hline 20 & 987 & ß-Myrcene & $\mathrm{C}_{10} \mathrm{H}_{16}$ & 2.58 & 127.57 & 5.65 & 185.79 & 7.14 & 236.85 & 10.63 & 456.27 & 7.23 & 292.61 \\
\hline 21 & 1004 & Octanal & $\mathrm{C}_{8} \mathrm{H}_{16} \mathrm{O}$ & 1.90 & 93.92 & 0.08 & 2.53 & - & - & 0.01 & 0.36 & 1.45 & 58.70 \\
\hline 22 & 1006 & a-Phellandrene & $\mathrm{C}_{10} \mathrm{H}_{16}$ & - & - & - & - & 0.19 & 6.18 & - & - & 1.91 & 77.27 \\
\hline 23 & 1017 & a-Terpinene & $\mathrm{C}_{10} \mathrm{H}_{16}$ & - & - & - & - & 0.04 & 1.33 & - & - & 0.45 & 18.30 \\
\hline 24 & 1020 & $\rho$-Cymene & $\mathrm{C}_{10} \mathrm{H}_{14}$ & - & - & - & - & 0.02 & 0.73 & - & - & 0.06 & 2.43 \\
\hline 25 & 1029 & Limonene & $\mathrm{C}_{10} \mathrm{H}_{16}$ & 42.57 & $2,102.93$ & 62.18 & $2,043.67$ & 51.99 & $1,724.75$ & 50.21 & $2,155.68$ & 51.38 & $2,099.09$ \\
\hline 26 & 1047 & (E)- $\beta$-Ocimene & $\mathrm{C}_{10} \mathrm{H}_{16}$ & 1.70 & 84.06 & 0.42 & 13.91 & 1.15 & 38.12 & 0.01 & 0.31 & 0.46 & 18.58 \\
\hline I.S & 1055 & Butyl-benzene & $\mathrm{C}_{10} \mathrm{H}_{14}$ & - & - & - & - & - & - & - & - & - & - \\
\hline 27 & 1058 & z-Terpinene & $\mathrm{C}_{10} \mathrm{H}_{16}$ & 0.75 & 37.05 & 0.23 & 7.41 & 4.00 & 132.61 & 0.15 & 6.31 & 0.68 & 27.63 \\
\hline 28 & 1073 & 1-Octanol & $\mathrm{C}_{8} \mathrm{H}_{18} \mathrm{O}$ & 0.30 & 14.85 & 0.09 & 2.94 & 0.12 & 4.13 & 0.01 & 0.60 & 0.25 & 10.03 \\
\hline 29 & 1076 & (Z)-Sabinene hydrate & $\mathrm{C}_{10} \mathrm{H}_{18} \mathrm{O}$ & 0.30 & 14.60 & 0.05 & 1.75 & 0.04 & 1.35 & 0.05 & 2.01 & 0.05 & 2.01 \\
\hline 30 & 1090 & a-Terpinolene & $\mathrm{C}_{10} \mathrm{H}_{16}$ & 0.25 & 12.19 & 0.09 & 2.84 & 1.22 & 40.52 & 0.09 & 3.83 & 1.22 & 49.48 \\
\hline 31 & 1095 & $\rho$-Cymenene & $\mathrm{C}_{10} \mathrm{H}_{12}$ & - & - & - & - & - & - & 0.08 & 3.43 & - & - \\
\hline 32 & 1101 & Linalool & $\mathrm{C}_{10} \mathrm{H}_{18} \mathrm{O}$ & 5.17 & 255.24 & 0.87 & 28.53 & 0.74 & 24.62 & 2.14 & 92.01 & 4.81 & 194.94 \\
\hline 33 & 1105 & Nonanal & $\mathrm{C}_{9} \mathrm{H}_{18} \mathrm{O}$ & 0.69 & 34.01 & 1.21 & 39.60 & 0.90 & 29.95 & 0.40 & 17.38 & 0.32 & 12.85 \\
\hline 34 & 1115 & 1,3,8-p-Menthatriene & $\mathrm{C}_{10} \mathrm{H}_{14}$ & 0.13 & 6.66 & 0.13 & 4.43 & 0.08 & 2.52 & 0.03 & 1.43 & 0.07 & 2.66 \\
\hline 35 & 1122 & $\beta$-Thujone & $\mathrm{C}_{10} \mathrm{H}_{16} \mathrm{O}$ & - & - & - & - & - & - & 0.02 & 0.92 & - & - \\
\hline 36 & 1124 & (E)-p-Mentha-2,8-dienol & $\mathrm{C}_{10} \mathrm{H}_{18} \mathrm{O}$ & 1.12 & 55.50 & 0.12 & 3.78 & 0.13 & 4.36 & 0.29 & 12.66 & 0.11 & 4.37 \\
\hline 37 & 1128 & (Z)-p-Menth-2-en-1-ol & $\mathrm{C}_{10} \mathrm{H}_{18} \mathrm{O}$ & 0.17 & 8.25 & 0.38 & 12.41 & 0.02 & 0.61 & 0.03 & 1.14 & 0.03 & 1.25 \\
\hline 38 & 1136 & (Z)-Limonene oxide & $\mathrm{C}_{10} \mathrm{H}_{16} \mathrm{O}$ & 0.94 & 46.46 & 0.40 & 13.00 & 0.30 & 9.79 & 0.33 & 14.09 & 0.26 & 10.34 \\
\hline 39 & 1140 & (E)-Limonene oxide & $\mathrm{C}_{10} \mathrm{H}_{16} \mathrm{O}$ & 1.69 & 83.55 & 0.61 & 19.99 & 0.43 & 14.38 & 0.74 & 31.82 & 0.36 & 14.64 \\
\hline 40 & 1152 & Citronellal & $\mathrm{C}_{10} \mathrm{H}_{18} \mathrm{O}$ & 0.61 & 30.29 & 0.64 & 20.99 & 0.41 & 13.77 & 1.16 & 49.67 & 1.97 & 79.68 \\
\hline 41 & 1160 & (E)-2-Nonenal & $\mathrm{C}_{9} \mathrm{H}_{16} \mathrm{O}$ & - & - & - & - & 0.02 & 0.61 & - & - & - & - \\
\hline 42 & 1167 & Isoborneol & $\mathrm{C}_{10} \mathrm{H}_{18} \mathrm{O}$ & - & - & - & - & 0.02 & 0.81 & - & - & - & - \\
\hline 43 & 1170 & (E)- $\beta$-Terpineol & $\mathrm{C}_{10} \mathrm{H}_{18} \mathrm{O}$ & 0.11 & 5.61 & 0.15 & 4.83 & 0.16 & 5.18 & 0.04 & 1.86 & 0.09 & 3.80 \\
\hline 44 & 1173 & 1-Nonanol & $\mathrm{C}_{9} \mathrm{H}_{20} \mathrm{O}$ & 0.21 & 10.16 & - & - & - & - & - & - & - & - \\
\hline 45 & 1175 & Borneol & $\mathrm{C}_{10} \mathrm{H}_{18} \mathrm{O}$ & - & - & 0.06 & 1.85 & 0.05 & 1.79 & - & - & - & - \\
\hline 46 & 1180 & 1-p-Menthen-9-al & $\mathrm{C}_{10} \mathrm{H}_{16} \mathrm{O}$ & 0.40 & 19.68 & - & - & - & - & - & - & - & - \\
\hline 47 & 1183 & 4-Terpineol & $\mathrm{C}_{10} \mathrm{H}_{18} \mathrm{O}$ & 2.65 & 130.67 & 0.21 & 6.94 & 0.28 & 9.40 & 0.35 & 14.82 & 0.32 & 12.77 \\
\hline 48 & 1189 & p-Cymen-8-ol & $\mathrm{C}_{10} \mathrm{H}_{14} \mathrm{O}$ & - & - & - & - & - & - & - & - & 0.06 & 2.45 \\
\hline 49 & 1191 & (E)-Isocarveol & $\mathrm{C}_{10} \mathrm{H}_{16} \mathrm{O}$ & 0.32 & 15.90 & - & - & - & - & - & - & - & - \\
\hline 50 & 1194 & Methyl salicylate & $\mathrm{C}_{8} \mathrm{H}_{8} \mathrm{O}_{3}$ & 0.18 & 8.80 & - & - & - & - & - & - & - & - \\
\hline
\end{tabular}


Table 1. Continued

\begin{tabular}{|c|c|c|c|c|c|c|c|c|c|c|c|c|c|}
\hline \multirow{2}{*}{ No } & \multirow{2}{*}{$\mathrm{RI}^{1)}$} & \multirow{2}{*}{ Compound Name } & \multirow{2}{*}{$\mathrm{MF}^{2)}$} & \multicolumn{2}{|c|}{ Cheonhyehyang } & \multicolumn{2}{|c|}{ Hallabong } & \multicolumn{2}{|c|}{ Jinjihyang } & \multicolumn{2}{|c|}{ Hwanggeumhyang } & \multicolumn{2}{|c|}{ Redhyang } \\
\hline & & & & area\% & $\mathrm{mg} / \mathrm{kg}$ & area\% & $\mathrm{mg} / \mathrm{kg}$ & area\% & $\mathrm{mg} / \mathrm{kg}$ & area\% & $\mathrm{mg} / \mathrm{kg}$ & area\% & $\mathrm{mg} / \mathrm{kg}$ \\
\hline 51 & 1196 & a-Terpineol & $\mathrm{C}_{10} \mathrm{H}_{18} \mathrm{O}$ & 1.64 & 81.09 & 0.35 & 11.58 & 1.00 & 33.10 & 0.39 & 16.88 & 0.95 & 38.52 \\
\hline 52 & 1206 & Decanal & $\mathrm{C}_{10} \mathrm{H}_{20} \mathrm{O}$ & 3.73 & 184.32 & 3.61 & 118.59 & 2.00 & 66.22 & 2.39 & 102.52 & 4.32 & 174.89 \\
\hline 53 & 1208 & Octyl acetate & $\mathrm{C}_{10} \mathrm{H}_{20} \mathrm{O}_{2}$ & - & - & - & - & 1.00 & 33.27 & - & - & - & - \\
\hline 54 & 1219 & (E)-Carveol & $\mathrm{C}_{10} \mathrm{H}_{16} \mathrm{O}$ & 2.26 & 111.41 & 0.28 & 9.07 & 0.25 & 8.30 & 0.39 & 16.82 & 0.24 & 9.54 \\
\hline 55 & 1227 & Citronellol & $\mathrm{C}_{10} \mathrm{H}_{20} \mathrm{O}$ & 0.11 & 5.43 & 0.71 & 23.49 & - & - & 0.65 & 27.78 & 0.44 & 17.83 \\
\hline 56 & 1233 & (Z)-Carveol & $\mathrm{C}_{10} \mathrm{H}_{16} \mathrm{O}$ & 1.05 & 51.94 & 0.06 & 1.83 & 0.06 & 2.06 & 0.10 & 4.41 & 0.07 & 2.94 \\
\hline 57 & 1238 & Neral & $\mathrm{C}_{10} \mathrm{H}_{16} \mathrm{O}$ & 0.05 & 2.46 & 0.02 & 0.60 & 0.04 & 1.27 & 0.02 & 0.79 & 0.02 & 0.66 \\
\hline 58 & 1245 & Carvone & $\mathrm{C}_{10} \mathrm{H}_{14} \mathrm{O}$ & 0.72 & 35.68 & 0.06 & 1.94 & 0.06 & 1.89 & 1.34 & 57.54 & 0.04 & 1.71 \\
\hline 59 & 1249 & Geraniol & $\mathrm{C}_{10} \mathrm{H}_{18} \mathrm{O}$ & 0.11 & 5.29 & 0.09 & 2.90 & 0.05 & 1.62 & - & - & - & - \\
\hline 60 & 1252 & Butyrophenone & $\mathrm{C}_{10} \mathrm{H}_{12} \mathrm{O}$ & 0.02 & 1.21 & 0.01 & 0.46 & 0.01 & 0.31 & 0.00 & 0.15 & 0.01 & 0.30 \\
\hline 61 & 1261 & (E)-2-Decenal & $\mathrm{C}_{10} \mathrm{H}_{18} \mathrm{O}$ & 0.09 & 4.50 & 0.11 & 3.72 & 0.14 & 4.78 & 0.06 & 2.63 & 0.09 & 3.44 \\
\hline 62 & 1267 & Geranial & $\mathrm{C}_{10} \mathrm{H}_{16} \mathrm{O}$ & 0.06 & 3.19 & 0.05 & 1.66 & 0.08 & 2.51 & 0.02 & 0.75 & 0.02 & 0.76 \\
\hline 63 & 1271 & Decanol & $\mathrm{C}_{10} \mathrm{H}_{22} \mathrm{O}$ & 0.16 & 7.86 & 0.06 & 1.91 & 0.06 & 2.01 & - & - & - & - \\
\hline 64 & 1278 & Perillaldehyde & $\mathrm{C}_{10} \mathrm{H}_{14} \mathrm{O}$ & 0.37 & 18.31 & 0.17 & 5.68 & 0.21 & 6.96 & 0.14 & 5.97 & 0.23 & 9.40 \\
\hline 65 & 1286 & Bornyl acetate & $\mathrm{C}_{12} \mathrm{H}_{20} \mathrm{O}_{2}$ & - & - & - & - & - & - & - & - & 0.02 & 0.64 \\
\hline 66 & 1289 & a-Terpinen-7-al & $\mathrm{C}_{10} \mathrm{H}_{14} \mathrm{O}$ & 0.04 & 1.90 & - & - & - & - & - & - & - & - \\
\hline 67 & 1291 & Limonen-10-ol & $\mathrm{C}_{10} \mathrm{H}_{16} \mathrm{O}$ & 3.01 & 148.88 & 0.06 & 1.99 & 0.09 & 3.15 & 0.04 & 1.63 & 0.05 & 2.09 \\
\hline 68 & 1297 & Carvacrol & $\mathrm{C}_{10} \mathrm{H}_{14} \mathrm{O}$ & - & - & - & - & - & - & - & - & 0.02 & 0.95 \\
\hline 69 & 1301 & p-Menth-1-en-9-ol & $\mathrm{C}_{10} \mathrm{H}_{18} \mathrm{O}$ & 0.16 & 7.90 & 0.14 & 4.44 & - & - & - & - & - & - \\
\hline 70 & 1302 & Perilla alcohol & $\mathrm{C}_{10} \mathrm{H}_{16} \mathrm{O}$ & 0.22 & 10.85 & - & - & - & - & - & - & - & - \\
\hline 71 & 1307 & Undecanal & $\mathrm{C}_{11} \mathrm{H}_{22} \mathrm{O}$ & 0.60 & 29.62 & 0.70 & 23.05 & 0.65 & 21.56 & 0.19 & 8.12 & 0.20 & 8.27 \\
\hline 72 & 1310 & 4-Vinyl-guaiacol & $\mathrm{C}_{9} \mathrm{H}_{10} \mathrm{O}_{2}$ & - & - & - & - & - & - & 0.06 & 2.53 & 0.05 & 2.10 \\
\hline 73 & 1318 & (E,E)-2,4-Decadienal & $\mathrm{C}_{10} \mathrm{H}_{16} \mathrm{O}$ & 0.10 & 4.91 & 0.11 & 3.61 & 0.08 & 2.69 & 0.05 & 2.07 & 0.05 & 1.85 \\
\hline 74 & 1324 & Myrtenyl acetate & $\mathrm{C}_{12} \mathrm{H}_{18} \mathrm{O}_{2}$ & 0.07 & 3.56 & 0.03 & 0.91 & - & - & - & - & - & - \\
\hline 75 & 1332 & (E)-Carvyl acetate & $\mathrm{C}_{12} \mathrm{H}_{18} \mathrm{O}_{2}$ & 0.15 & 7.53 & - & - & - & - & 0.19 & 8.03 & - & - \\
\hline 76 & 1334 & Bicycloelemene & $\mathrm{C}_{15} \mathrm{H}_{24}$ & - & - & - & - & - & - & - & - & 0.06 & 2.26 \\
\hline 77 & 1337 & 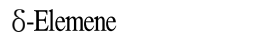 & $\mathrm{C}_{15} \mathrm{H}_{24}$ & - & - & 0.09 & 2.79 & 0.85 & 28.29 & 0.03 & 1.40 & 0.06 & 2.59 \\
\hline 78 & 1347 & Citronellyl acetate & $\mathrm{C}_{12} \mathrm{H}_{22} \mathrm{O}_{2}$ & 0.09 & 4.31 & 0.78 & 25.49 & 0.26 & 8.66 & 1.11 & 47.48 & 0.08 & 3.36 \\
\hline 79 & 1349 & a-Cubebene & $\mathrm{C}_{1} 5 \mathrm{H}_{24}$ & - & - & - & - & - & - & - & - & 0.01 & 0.47 \\
\hline 80 & 1356 & Neryl acetate & $\mathrm{C}_{12} \mathrm{H}_{20} \mathrm{O}_{2}$ & 0.12 & 5.74 & 0.32 & 10.62 & 0.43 & 14.38 & 0.47 & 20.06 & 0.00 & 0.17 \\
\hline 81 & 1359 & (Z)-Carvyl acetate & $\mathrm{C}_{12} \mathrm{H}_{18} \mathrm{O}_{2}$ & 0.25 & 12.41 & - & - & - & - & 0.29 & 12.26 & - & - \\
\hline 82 & 1361 & Decanoic acid & $\mathrm{C}_{10} \mathrm{H}_{20} \mathrm{O}_{2}$ & 0.07 & 3.60 & 0.15 & 4.82 & 0.05 & 1.81 & - & - & 0.09 & 3.51 \\
\hline 83 & 1364 & (E)-2-Undecenal & $\mathrm{C}_{11} \mathrm{H}_{20} \mathrm{O}$ & - & - & - & - & 0.04 & 1.23 & - & - & - & - \\
\hline 84 & 1376 & Geranyl acetate & $\mathrm{C}_{12} \mathrm{H}_{20} \mathrm{O}_{2}$ & 0.20 & 9.71 & 0.05 & 1.48 & 0.73 & 24.13 & 0.09 & 4.02 & 0.03 & 1.09 \\
\hline 85 & 1378 & a-Copaene & $\mathrm{C}_{15} \mathrm{H}_{24}$ & 0.07 & 3.64 & 0.09 & 2.81 & 0.02 & 0.60 & 0.26 & 11.24 & 0.05 & 2.11 \\
\hline 86 & 1391 & $\beta$-Elemene & $\mathrm{C}_{15} \mathrm{H}_{24}$ & 0.45 & 22.17 & 0.18 & 5.77 & 0.45 & 15.00 & 0.38 & 16.47 & 0.13 & 5.19 \\
\hline 87 & 1402 & a-Funebrene & $\mathrm{C}_{15} \mathrm{H}_{24}$ & 0.03 & 1.42 & - & - & 0.04 & 1.23 & 0.11 & 4.57 & - & - \\
\hline 88 & 1407 & Decyl acetate & $\mathrm{C}_{12} \mathrm{H}_{24} \mathrm{O}_{2}$ & 0.06 & 3.20 & 0.04 & 1.24 & 0.64 & 21.13 & 0.08 & 3.43 & - & - \\
\hline 89 & 1409 & Dodecanal & $\mathrm{C}_{12} \mathrm{H}_{24} \mathrm{O}$ & 1.88 & 93.02 & 0.94 & 30.97 & 0.59 & 19.69 & 0.53 & 22.89 & 1.03 & 41.74 \\
\hline 90 & 1419 & p-Menth-1-en-9-ol acetate & $\mathrm{C}_{12} \mathrm{H}_{20} \mathrm{O}_{2}$ & 0.09 & 4.27 & 0.02 & 0.62 & 0.02 & 0.82 & 0.03 & 1.14 & 0.00 & 0.14 \\
\hline 91 & 1422 & $\beta$-Ylangene & $\mathrm{C}_{15} \mathrm{H}_{24}$ & - & - & - & - & 0.05 & 1.58 & - & - & - & - \\
\hline 92 & 1425 & (E)-B-Caryophyllene & $\mathrm{C}_{15} \mathrm{H}_{24}$ & 0.06 & 3.10 & 0.05 & 1.79 & 0.42 & 14.09 & 0.17 & 7.10 & 0.05 & 2.02 \\
\hline 93 & 1431 & z-Elemene & $\mathrm{C}_{15} \mathrm{H}_{24}$ & - & - & 0.05 & 1.59 & 0.19 & 6.20 & 0.01 & 0.30 & 0.02 & 0.81 \\
\hline 94 & 1434 & Perillyl acetate & $\mathrm{C}_{12} \mathrm{H}_{18} \mathrm{O}_{2}$ & 0.04 & 1.99 & - & - & 0.13 & 4.36 & 0.02 & 0.84 & 0.01 & 0.46 \\
\hline 95 & 1438 & a-Guaiene & $\mathrm{C}_{15} \mathrm{H}_{24}$ & - & - & - & - & 0.04 & 1.38 & - & - & 0.01 & 0.48 \\
\hline 96 & 1444 & Guaia-6,9-diene & $\mathrm{C}_{15} \mathrm{H}_{24}$ & - & - & - & - & 0.02 & 0.66 & - & - & - & - \\
\hline 97 & 1447 & (E,Z)-2,6-Dodecadienal & $\mathrm{C}_{12} \mathrm{H}_{20} \mathrm{O}$ & 0.04 & 1.97 & 0.05 & 1.79 & 0.05 & 1.64 & 0.03 & 1.48 & 0.02 & 0.61 \\
\hline 98 & 1452 & (E)- $\beta$-Farnesene & $\mathrm{C}_{15} \mathrm{H}_{24}$ & 0.38 & 18.83 & 0.07 & 2.33 & 0.63 & 20.92 & 3.09 & 132.84 & 0.04 & 1.67 \\
\hline 99 & 1454 & Sesquisabinene & $\mathrm{C}_{15} \mathrm{H}_{24}$ & 0.10 & 4.75 & 0.03 & 0.86 & 0.09 & 2.89 & - & - & - & - \\
\hline 100 & 1460 & a-Humulene & $\mathrm{C}_{15} \mathrm{H}_{24}$ & 0.09 & 4.47 & 0.06 & 2.00 & 0.12 & 4.12 & 0.06 & 2.59 & 0.04 & 1.77 \\
\hline 101 & 1467 & (E)-2-Dodecenal & $\mathrm{C}_{12} \mathrm{H}_{22} \mathrm{O}$ & 0.03 & 1.57 & 0.03 & 0.89 & 0.06 & 1.83 & 0.02 & 0.97 & 0.02 & 0.65 \\
\hline
\end{tabular}


Table 1. Continued

\begin{tabular}{|c|c|c|c|c|c|c|c|c|c|c|c|c|c|}
\hline \multirow{2}{*}{ No } & \multirow{2}{*}{$\mathrm{RI}^{1)}$} & \multirow{2}{*}{ Compound Name } & \multirow{2}{*}{$\mathrm{MF}^{2}$} & \multicolumn{2}{|c|}{ Cheonhyehyang } & \multicolumn{2}{|c|}{ Hallabong } & \multicolumn{2}{|c|}{ Jinjihyang } & \multicolumn{2}{|c|}{ Hwanggeumhyang } & \multicolumn{2}{|c|}{ Redhyang } \\
\hline & & & & area $\%$ & $\mathrm{mg} / \mathrm{kg}$ & area\% & $\mathrm{mg} / \mathrm{kg}$ & area\% & $\mathrm{mg} / \mathrm{kg}$ & area\% & $\mathrm{mg} / \mathrm{kg}$ & area\% & $\mathrm{mg} / \mathrm{kg}$ \\
\hline 102 & 1480 & 8 -Gurjunene & $\mathrm{C}_{15} \mathrm{H}_{24}$ & - & - & 0.02 & 0.66 & - & - & 0.07 & 2.80 & 0.01 & 0.48 \\
\hline 103 & 1488 & Germacrene D & $\mathrm{C}_{15} \mathrm{H}_{24}$ & 0.02 & 0.86 & 0.16 & 5.32 & 3.17 & 105.18 & 0.15 & 6.33 & 0.15 & 6.21 \\
\hline 104 & 1489 & $\beta$-Chamigrene & $\mathrm{C}_{15} \mathrm{H}_{24}$ & - & - & 0.12 & 3.90 & - & - & - & - & - & - \\
\hline 105 & 1489 & Selina-4,11-diene & $\mathrm{C}_{15} \mathrm{H}_{24}$ & - & - & - & - & - & - & 0.18 & 7.92 & - & - \\
\hline 106 & 1490 & $\beta$-Selinene & $\mathrm{C}_{15} \mathrm{H}_{24}$ & - & - & - & - & 0.03 & 0.97 & - & - & 0.05 & 2.20 \\
\hline 107 & 1496 & Valencene & $\mathrm{C}_{15} \mathrm{H}_{24}$ & 0.11 & 5.61 & 1.45 & 47.72 & 0.19 & 6.46 & 2.81 & 120.61 & 0.79 & 32.01 \\
\hline 108 & 1500 & Bicyclogermacrene & $\mathrm{C}_{15} \mathrm{H}_{24}$ & - & - & - & - & 0.14 & 4.81 & 0.64 & 27.32 & 0.66 & 26.84 \\
\hline 109 & 1501 & a-Selinene & $\mathrm{C}_{15} \mathrm{H}_{24}$ & - & - & 0.12 & 3.82 & - & - & - & - & - & - \\
\hline 110 & 1503 & (E,E)-a-Farnesene & $\mathrm{C}_{15} \mathrm{H}_{24}$ & 0.24 & 12.02 & 2.40 & 78.84 & 0.73 & 24.30 & 1.70 & 73.07 & 0.92 & 37.22 \\
\hline 111 & 1508 & a-Bulnesene & $\mathrm{C}_{15} \mathrm{H}_{24}$ & - & - & 0.03 & 0.95 & - & - & 0.12 & 5.07 & 0.02 & 0.65 \\
\hline 112 & 1510 & Tridecanal & $\mathrm{C}_{13} \mathrm{H}_{26} \mathrm{O}$ & 0.03 & 1.43 & 0.02 & 0.62 & 0.02 & 0.76 & - & - & 0.00 & 0.19 \\
\hline 113 & 1516 & y-Cadinene & $\mathrm{C}_{15} \mathrm{H}_{24}$ & - & - & - & - & 0.02 & 0.54 & - & - & 0.01 & 0.53 \\
\hline 114 & 1520 & S-Cadinene & $\mathrm{C}_{15} \mathrm{H}_{24}$ & 0.07 & 3.55 & 0.13 & 4.12 & 0.06 & 2.10 & 0.36 & 15.52 & 0.16 & 6.60 \\
\hline 115 & 1524 & 7-Epi-a-selinene & $\mathrm{C}_{15} \mathrm{H}_{24}$ & - & - & - & - & - & - & - & - & 0.05 & 2.00 \\
\hline 116 & 1525 & $\beta$-Sesquiphellandrene & $\mathrm{C}_{15} \mathrm{H}_{24}$ & 0.04 & 2.12 & 0.09 & 2.95 & 0.12 & 4.03 & 0.45 & 19.26 & - & - \\
\hline 117 & 1551 & a-Elemol & $\mathrm{C}_{15} \mathrm{H}_{26} \mathrm{O}$ & 0.01 & 0.43 & 0.05 & 1.65 & 0.02 & 0.51 & 0.07 & 2.85 & 0.03 & 1.25 \\
\hline 118 & 1556 & Dodecanoic acid & $\mathrm{C}_{12} \mathrm{H}_{24} \mathrm{O}_{2}$ & 0.05 & 2.31 & 0.03 & 0.89 & 0.04 & 1.23 & 0.05 & 2.16 & 0.04 & 1.48 \\
\hline 119 & 1560 & (E)-Nerolidol & $\mathrm{C}_{15} \mathrm{H}_{26} \mathrm{O}$ & 0.03 & 1.67 & 0.07 & 2.33 & - & - & 0.11 & 4.90 & 0.04 & 1.42 \\
\hline 120 & 1565 & Germacrene B & $\mathrm{C}_{15} \mathrm{H}_{24}$ & - & - & 0.02 & 0.55 & 0.27 & 8.94 & - & - & 0.02 & 0.74 \\
\hline 121 & 1582 & Spathulenol & $\mathrm{C}_{15} \mathrm{H}_{24} \mathrm{O}$ & 0.05 & 2.54 & 0.07 & 2.43 & 0.13 & 4.45 & 0.40 & 17.17 & 0.62 & 25.14 \\
\hline 122 & 1588 & Caryophyllene oxide & $\mathrm{C}_{15} \mathrm{H}_{24} \mathrm{O}$ & 0.04 & 2.17 & - & - & - & - & 0.17 & 7.29 & 0.02 & 0.73 \\
\hline 123 & 1590 & Ethyl-dodecanoate & $\mathrm{C}_{14} \mathrm{H}_{28} \mathrm{O}_{2}$ & 0.03 & 1.67 & - & - & - & - & - & - & - & - \\
\hline 124 & 1600 & Viridiflorol & $\mathrm{C}_{15} \mathrm{H}_{26} \mathrm{O}$ & - & - & - & - & 0.04 & 1.36 & - & - & 0.01 & 0.58 \\
\hline 125 & 1605 & Dodecyl acetate & $\mathrm{C}_{14} \mathrm{H}_{28} \mathrm{O}_{2}$ & 0.01 & 0.61 & 0.00 & 0.13 & 0.06 & 1.96 & 0.01 & 0.46 & 0.01 & 0.41 \\
\hline 126 & 1612 & Tetradecanal & $\mathrm{C}_{14} \mathrm{H}_{28} \mathrm{O}$ & 0.04 & 2.16 & 0.05 & 1.54 & 0.07 & 2.18 & 0.05 & 2.27 & 0.04 & 1.61 \\
\hline 127 & 1617 & Humulene epoxide II & $\mathrm{C}_{15} \mathrm{H}_{24} \mathrm{O}$ & 0.02 & 1.17 & 0.03 & 1.01 & - & - & 0.04 & 1.51 & 0.01 & 0.21 \\
\hline 128 & 1633 & $\mathrm{\gamma}$-Eudesmol & $\mathrm{C}_{15} \mathrm{H}_{26} \mathrm{O}$ & - & - & 0.05 & 1.70 & 0.57 & 18.85 & 0.03 & 1.12 & 0.04 & 1.57 \\
\hline 129 & 1649 & T-Muurolol & $\mathrm{C}_{15} \mathrm{H}_{26} \mathrm{O}$ & 0.01 & 0.44 & 0.01 & 0.30 & - & - & 0.06 & 2.36 & 0.03 & 1.27 \\
\hline 130 & 1660 & T-Cadinol & $\mathrm{C}_{15} \mathrm{H}_{26} \mathrm{O}$ & - & - & 0.03 & 0.87 & 0.10 & 3.45 & 0.09 & 3.99 & 0.09 & 3.80 \\
\hline 131 & 1665 & Neo-intermedeol & $\mathrm{C}_{15} \mathrm{H}_{26} \mathrm{O}$ & 0.02 & 0.92 & - & - & - & - & 0.04 & 1.78 & - & - \\
\hline 132 & 1672 & Intermedeol & $\mathrm{C}_{15} \mathrm{H}_{26} \mathrm{O}$ & - & - & - & - & - & - & 0.22 & 9.52 & 0.04 & 1.65 \\
\hline 133 & 1676 & Tetradecanol & $\mathrm{C}_{14} \mathrm{H}_{30} \mathrm{O}$ & - & - & - & - & - & - & 0.08 & 3.62 & - & - \\
\hline 134 & 1694 & $\beta$-Sinensal & $\mathrm{C}_{15} \mathrm{H}_{22} \mathrm{O}$ & 0.35 & 17.51 & - & - & 0.75 & 24.94 & 1.10 & 47.23 & - & - \\
\hline 135 & 1710 & (E,Z)-2,6-Farnesal & $\mathrm{C}_{15} \mathrm{H}_{24} \mathrm{O}$ & 0.01 & 0.33 & 0.01 & 0.31 & - & - & 0.03 & 1.20 & 0.01 & 0.40 \\
\hline 136 & 1713 & Pentadecanal & $\mathrm{C}_{15} \mathrm{H}_{30} \mathrm{O}$ & - & - & - & - & 0.01 & 0.22 & - & - & 0.01 & 0.60 \\
\hline 137 & 1715 & (E,E)-2,6-Farnesol & $\mathrm{C}_{15} \mathrm{H}_{26} \mathrm{O}$ & - & - & - & - & - & - & 0.53 & 22.93 & - & - \\
\hline 138 & 1727 & (Z,E)-a-Bergamotol & $\mathrm{C}_{15} \mathrm{H}_{24} \mathrm{O}$ & - & - & - & - & 0.02 & 0.55 & - & - & 0.04 & 1.51 \\
\hline 139 & 1737 & (E,E)-Farnesal & $\mathrm{C}_{15} \mathrm{H}_{24} \mathrm{O}$ & 0.03 & 1.50 & 0.02 & 0.51 & 0.02 & 0.66 & 0.06 & 2.49 & 0.09 & 3.55 \\
\hline 140 & 1739 & Oplopanone & $\mathrm{C}_{15} \mathrm{H}_{26} \mathrm{O}_{2}$ & - & - & - & - & 0.02 & 0.56 & - & - & 0.01 & 0.35 \\
\hline 141 & 1751 & a-Sinensal & $\mathrm{C}_{15} \mathrm{H}_{22} \mathrm{O}$ & 0.25 & 12.27 & 0.06 & 2.01 & 1.52 & 50.28 & 1.34 & 57.49 & 3.13 & 126.93 \\
\hline 142 & 1755 & Tetradecanoic acid & $\mathrm{C}_{14} \mathrm{H}_{28} \mathrm{O}_{2}$ & 0.05 & 2.37 & 0.01 & 0.24 & 0.04 & 1.23 & 0.02 & 1.00 & - & - \\
\hline 143 & 1810 & Nootkatone & $\mathrm{C}_{15} \mathrm{H}_{22} \mathrm{O}$ & 0.05 & 2.33 & 0.67 & 21.91 & 0.12 & 4.09 & 0.33 & 14.07 & 0.35 & 14.19 \\
\hline 144 & 1815 & Hexadecanal & $\mathrm{C}_{16} \mathrm{H}_{32} \mathrm{O}$ & 0.05 & 2.51 & 0.07 & 2.41 & 0.06 & 1.84 & 0.11 & 4.52 & 0.04 & 1.73 \\
\hline 145 & 1961 & Palmitic acid & $\mathrm{C}_{16} \mathrm{H}_{32} \mathrm{O}_{2}$ & 0.74 & 36.59 & 0.43 & 14.20 & 0.97 & 32.15 & 0.29 & 12.27 & - & - \\
\hline 146 & 2091 & Methyl linoleate & $\mathrm{C}_{19} \mathrm{H}_{34} \mathrm{O}_{2}$ & 0.02 & 0.88 & - & - & - & - & - & - & 0.01 & 0.34 \\
\hline 147 & 2129 & Linoleic acid & $\mathrm{C}_{18} \mathrm{H}_{32} \mathrm{O}_{2}$ & 0.50 & 24.73 & 0.14 & 4.66 & 0.29 & 9.64 & 0.08 & 3.47 & 0.30 & 12.08 \\
\hline 148 & 2134 & Oleic acid & $\mathrm{C}_{18} \mathrm{H}_{34} \mathrm{O}_{2}$ & 0.94 & 46.64 & 0.18 & 6.06 & 0.28 & 9.14 & 0.10 & 4.40 & 0.34 & 13.97 \\
\hline 149 & 2160 & Ethyl linoleate & $\mathrm{C}_{20} \mathrm{H}_{36} \mathrm{O}_{2}$ & - & - & - & - & - & - & 0.01 & 0.60 & - & - \\
\hline 150 & 2169 & Ethyl linolenate & $\mathrm{C}_{20} \mathrm{H}_{34} \mathrm{O}_{2}$ & - & - & - & - & - & - & 0.01 & 0.46 & - & - \\
\hline & & Total & & 100 & $4,939.77$ & 100 & $3,286.38$ & 100 & $3,317.56$ & 100 & $4,293.39$ & 100 & $4,049.94$ \\
\hline
\end{tabular}

${ }^{1)}$ Retention index.

${ }^{2)}$ Molecular formula 
Table 2. Relative contents of the functional groups in the volatile compounds detected in Jeju citrus fruits

\begin{tabular}{|c|c|c|c|c|c|c|c|c|c|c|c|c|c|c|c|}
\hline \multirow{2}{*}{ Functional group } & \multicolumn{3}{|c|}{ Cheonhyehyang } & \multicolumn{3}{|c|}{ Hallabong } & \multicolumn{3}{|c|}{ Jinjihyang } & \multicolumn{3}{|c|}{ Hwanggeumhyang } & \multicolumn{3}{|c|}{ Redhyang } \\
\hline & NO. & Area\% & $\mathrm{mg} / \mathrm{kg}$ & NO. & Area\% & $\mathrm{mg} / \mathrm{kg}$ & NO. & Area\% & $\mathrm{mg} / \mathrm{kg}$ & NO. & Area\% & $\mathrm{mg} / \mathrm{kg}$ & NO. & Area\% & $\mathrm{mg} / \mathrm{kg}$ \\
\hline Alcohols & 24 & 18.94 & 935.79 & 23 & 3.92 & 128.89 & 22 & 3.95 & 130.97 & 25 & 6.18 & 265.37 & 26 & 8.57 & 347.17 \\
\hline Aldehydes & 25 & 11.55 & 570.62 & 22 & 8.18 & 268.69 & 25 & 8.88 & 294.73 & 22 & 7.88 & 338.33 & 24 & 13.20 & 534.57 \\
\hline Esters & 15 & 2.46 & 121.76 & 9 & 2.55 & 83.76 & 9 & 3.32 & 110.05 & 13 & 2.57 & 110.28 & 10 & 0.66 & 26.57 \\
\hline Hydrocarbons & 25 & 61.04 & $3,015.36$ & 29 & 82.43 & $2,708.96$ & 35 & 81.10 & $2,690.42$ & 29 & 79.79 & $3,425.66$ & 36 & 75.67 & $3,064.68$ \\
\hline Ketones & 5 & 0.94 & 46.65 & 5 & 0.95 & 31.21 & 6 & 0.36 & 12.01 & 4 & 1.69 & 72.68 & 4 & 0.41 & 16.56 \\
\hline Oxides & 4 & 2.70 & 133.35 & 3 & 1.03 & 34.00 & 2 & 0.73 & 24.17 & 4 & 1.27 & 54.70 & 4 & 0.64 & 25.92 \\
\hline Acids & 6 & 2.35 & 116.24 & 6 & 0.94 & 30.87 & 6 & 1.66 & 55.20 & 5 & 0.61 & 26.36 & 4 & 0.85 & 34.47 \\
\hline Total & 104 & 100 & $4,939.77$ & 97 & 100 & $3,286.38$ & 105 & 100 & $3,317.56$ & 102 & 100 & $4,293.39$ & 108 & 100 & 4,049.94 \\
\hline
\end{tabular}

Table 3. Comparison of the relative contents of terpenoids in Jeju citrus fruits

\begin{tabular}{|c|c|c|c|c|c|c|c|c|c|c|c|c|c|c|c|}
\hline \multirow{2}{*}{ Terpenoids } & \multicolumn{3}{|c|}{ Cheonhyehyang } & \multicolumn{3}{|c|}{ Hallabong } & \multicolumn{3}{|c|}{ Jinjihyang } & \multicolumn{3}{|c|}{ Hwanggeumhyang } & \multicolumn{3}{|c|}{ Redhyang } \\
\hline & NO. & Area\% & $\mathrm{mg} / \mathrm{kg}$ & NO. & Area\% & $\mathrm{mg} / \mathrm{kg}$ & NO. & Area\% & $\mathrm{mg} / \mathrm{kg}$ & NO. & Area\% & $\mathrm{mg} / \mathrm{kg}$ & NO. & Area\% & $\mathrm{mg} / \mathrm{kg}$ \\
\hline Monoterpene hydrocarbons & 11 & 59.36 & $2,932.01$ & 11 & 77.29 & $2,540.20$ & 14 & 73.44 & $2,436.16$ & 12 & 69.21 & $2,971.24$ & 14 & 72.34 & $2,929.69$ \\
\hline Sesquiterpene hydrocarbons & 12 & 1.67 & 82.52 & 18 & 5.14 & 168.76 & 21 & 7.66 & 254.26 & 17 & 10.58 & 454.42 & 21 & 3.33 & 134.84 \\
\hline Oxygenated monoterpenes & 32 & 24.28 & $1,199.60$ & 26 & 6.65 & 218.39 & 26 & 7.01 & 232.54 & 26 & 10.42 & 447.38 & 26 & 10.29 & 416.54 \\
\hline Oxygenated sesquiterpenes & 12 & 0.88 & 43.28 & 11 & 1.07 & 35.02 & 11 & 3.31 & 109.69 & 16 & 4.61 & 197.91 & 16 & 4.56 & 184.55 \\
\hline Total & 67 & 86.19 & $4,257.41$ & 66 & 90.15 & $2,962.37$ & 72 & 91.42 & $3,032.65$ & 71 & 94.82 & $4,070.95$ & 77 & 90.52 & $3,665.62$ \\
\hline
\end{tabular}

Table 1에 나타내었다. 한라봉에서 확인된 휘발성 향기성분 은 97 종으로 함량은 $3,286.38 \mathrm{mg} / \mathrm{kg}$ 으로 동정되었다. 한라 봉의 휘발성 향기성분은 관능기별로는 hydrocarbon류가 29 종으로 가장 많았으며, 다음으로는 alcohol류와 aldehyde류 가 각각 23종 및 22종으로 동정되었고, ester류 9종, acid류 6종, ketone류 5종과 oxide류 3종이 확인되었다. 관능기별 함량은 hydrocarbon류가 $2,708.96 \mathrm{mg} / \mathrm{kg}$ 으로 가장 높게 확 인되었으며, aldehyde류 $268.69 \mathrm{mg} / \mathrm{kg}$, alcohol류 128.89 $\mathrm{mg} / \mathrm{kg}$, ester류 $83.76 \mathrm{mg} / \mathrm{kg}$, oxide류 $34.00 \mathrm{mg} / \mathrm{kg}$, ketone류 $31.21 \mathrm{mg} / \mathrm{kg}$ 및 acid류 $30.87 \mathrm{mg} / \mathrm{kg}$ 순으로 확인되었다(Fig. 2). 한라봉의 주요 휘발성 향기성분은 limonene으로 peak area가 $62.18 \%$ 로 함량은 $2,043.67 \mathrm{mg} / \mathrm{kg}$ 이 함유되어 있었 다. 다음으로 $\beta$-myrcene $185.79 \mathrm{mg} / \mathrm{kg}(5.65 \%)$, sabinene $133.59 \mathrm{mg} / \mathrm{kg}(4.06 \%)$, decanal $118.59 \mathrm{mg} / \mathrm{kg}(3.61 \%)$, a -pinene $81.68 \mathrm{mg} / \mathrm{kg}(2.49 \%)$, (E,E)-a-farnesene $78.84 \mathrm{mg} / \mathrm{kg}$ (2.40\%), $\beta$-pinene $63.18 \mathrm{mg} / \mathrm{kg}(1.92 \%)$, valencene 47.72 $\mathrm{mg} / \mathrm{kg}(1.45 \%)$, ethyl acetate $41.53 \mathrm{mg} / \mathrm{kg}(1.26 \%)$ 및 nonanal $39.60 \mathrm{mg} / \mathrm{kg}(1.21 \%)$ 등 순으로 확인되었다. 한라봉의 휘발 성 화합물 중 terpene류는 66종으로 전체 향기성분의 $90.15 \%$ 를 차지하여 $2,962.37 \mathrm{mg} / \mathrm{kg}$ 의 함량을 나타내었다 (Table 3).

Monoterpene hydrocarbon류(77.29\%)의 함량이 높았으 며, 그 다음으로 oxygenated monoterpene류(6.65\%)가 차지 하였다(Fig. 3). 한라봉의 monoterpene hydrocarbon류는 limonene, sabinene, $\beta$-pinene, a-thujene, (E)- $\beta$-ocimene, $\gamma$ -terpinene 및 a-terpinolene 등으로 동정되었다. Sesquiterpene hydrocarbon류는 $\delta$-elemene, a-copaene, (E)- $\beta$-caryo phyllene, $\gamma$-elemene, aromadendrene, (E)- $\beta$-farnesene, sesquisabinene, a-humulene, $\gamma$-gurjunene, germacrene $\mathrm{D}, \beta$-chamigrene, a -selinene, valencene, $\delta$-guaiene 및 7-epi-a-selinene 및 등이 확인되었다. Oxygenated monoterpene류는 linalool, (E)-pmentha-2,8-dienol, (Z)-p-menth-2-en-1-ol, (Z)-Limonene oxide, (Z)- $\rho$-mentha-2,8-dienol, (Z)- $\beta$-terpineol, citronellal, (E)- $\beta$

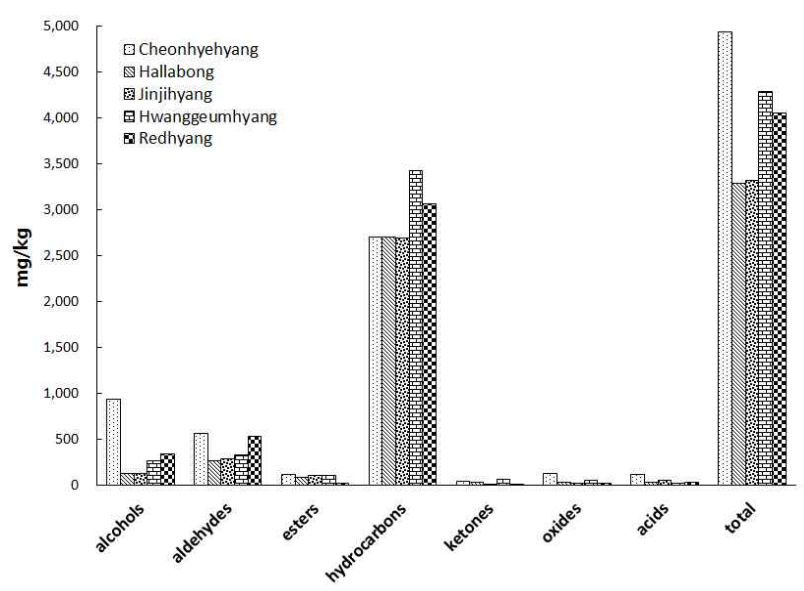

Fig. 2. Relative contents of the functional groups in the volatile compounds detected in Jeju citrus fruits. 


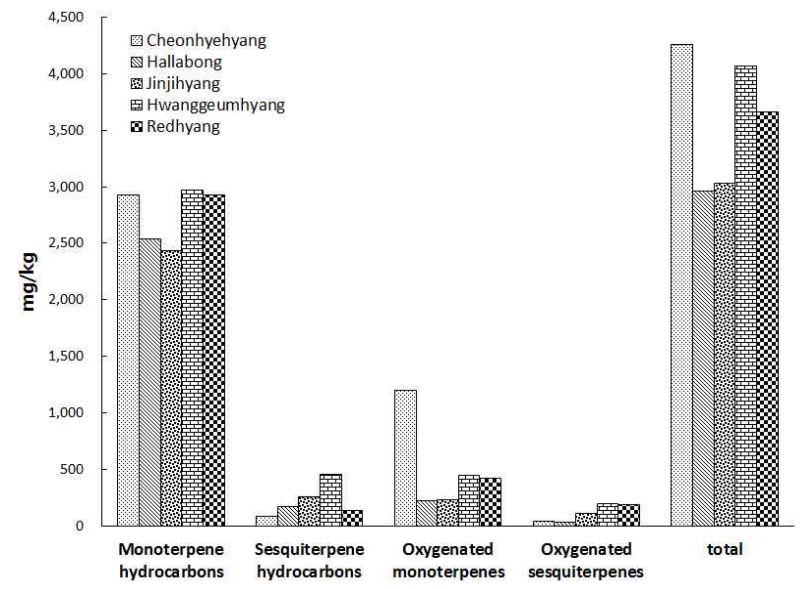

Fig. 3. Comparison of the relative contents of terpenoids in Jeju citrus fruits.

-terpineol, 4-terpineol, a-terpineol, (E)-carveol 및 (Z)-carveol 등이 확인되었다.

Oxygenated sesquiterpene류는 a-elemol, (E)-nerolidol, spathulenol, humulene epoxide II, $\gamma$-eudesmol, valerianol, T-cadinol, a-sinensal 및 nootkatone 등이 확인되었다. 강(21) 은 한라봉 에센셜 오일에서 sabinene, $\beta$-myrcene 및 a -farnesene의 함량을 각각 $1.13,1.39 \%$ 및 $0.24 \%$ 로 보고하였 으며, 유(29)는 한라봉에서 (Z)- $\beta$-ocimene, valencene, a -farnesene의 함량은 많고 sabinene과 isothujol 및 $\delta$-elemene 은 적은 양이 함유되어 있다고 보고하였다. 본 연구에서는 한라봉에서 확인된 sabinene, $\beta$-myrcene 및 a-farnesene의 상대적 비율이 강(21)의 연구결과보다 높았고, $(\mathrm{Z})-\beta$ -ocimene 및 isothujol은 확인되지 않았으며, (E)- $\beta$-ocimene 과 $\delta$-elemene은 낮은 비율로 동정되었다. $\beta$-Chamigrene 및 a-selinene은 제주감귤류 중 한라봉에서만 확인된 성분 이다.

\section{진지향의 휘발성 향기성분}

진지향의 휘발성 향기성분은 $\mathrm{SDE}$ 방법을 이용하여 추출 한 후 GC/MS로 분석한 화합물들의 상대적 농도를 Table 1에 나타내었고, chromatogram은 Fig. 1에 도식하였다. 진지 향에서 확인된 휘발성 화합물은 105 종으로 함량은 $3,317.56$ $\mathrm{mg} / \mathrm{kg}$ 으로 확인되었다. 진지향의 휘발성 화합물은 관능기 별로는 hydrocarbon류가 35종으로 가장 많았으며, 그 다음 으로는 aldehyde류 25종, alcohol류 22종, ester류 9종, acid류 6종, ketone류 6종 및 oxide류 2종이 확인되었다. 관능기별 peak area는 hydrocarbon류가 $81.10 \%$ 로 가장 높았으며, aldehyde류 $8.88 \%$, alcohol류가 $3.95 \%$, ester류 $3.32 \%$, acid류 $1.66 \%$, oxide류 $0.73 \%$ 및 ketone류 $0.36 \%$ 순으로 나타났다. 진지향에서 확인된 주요 휘발성 향기성분은 limonene $51.99 \%(1,724.75 \mathrm{mg} / \mathrm{kg})$, $\beta$-myrcene $7.14 \%(236.85 \mathrm{mg} / \mathrm{kg})$, -terpinene $4.00 \%(132.61 \mathrm{mg} / \mathrm{kg})$, a-pinene $3.70 \%(122.79$ $\mathrm{mg} / \mathrm{kg})$, germacrene D 3.17\%(105.18 mg/kg), $\beta$-pinene $2.22 \%(73.61 \mathrm{mg} / \mathrm{kg})$ 및 decanal $2.00 \%(66.22 \mathrm{mg} / \mathrm{kg})$ 등 순으 로 나타났다. 진지향의 휘발성 화합물 중 terpene류는 72종 으로 전체 향기성분의 $91.42 \%$ 를 차지하여 $3,032.65 \mathrm{mg} / \mathrm{kg}$ 의 함량을 나타내었다(Table 3). Terpene류 중 monoterpene hydrocarbon류의 함량이 높았으며, 그 다음으로 sesquiterpene hydrocarbon류의 함량이 많았다(Fig. 3). 진지향에서 확인된 monoterpene hydrocarbon류는 limonene, a-thujene, sabinene, $\beta$-pinene, a-phellandrene, a-terpinene, $\rho$-cymene, (E)- $\beta$ -ocimene 및 $\mathrm{a}$-terpinolene 등이 동정된 향기성분이다. $\mathrm{a}$ -Terpinolene은 woody type으로 감미로운 향긋한 솔향, 달콤 한 파인애플 및 minty-camphoraceous 특징을 가진다(30). Sesquiterpene hydrocarbon류는 valencene, 7-epi-a-selinene, $\delta$-elemene, a-copaene, $\beta$-elemene, a-funebrene, $\beta$-ylangene 및 (E)- $\beta$-caryophyllene 등이 확인되었다. Oxygenated monoterpene류는 linalool, (E)-p-mentha-2,8-dienol, (Z)-pmenth-2-en-1-ol, (Z)-limonene oxide, (E)-limonene oxide, 4-terpineol, a-terpineol, (E)-carveol, (Z)-carveol 및 geraniol 등이 확인되었다. Oxygenated sesquiterpene류는 a-elemol, spathulenol, viridiflorol, $\gamma$-eudesmol, T-cadinol, $\beta$-sinensal, (Z,E)-a-bergamotol, (E,E)-farnesal, oplopanone, a-sinensal 및 nootkatone 등이 분석되었다. 3-Hydroxybutanal, (E)-2nonenal, isoborneol, octyl acetate, (E)-2-undecenal, $\beta$ -ylangene 및 guaia-6,9-diene 등은 진지향에서만 확인되 었다.

\section{황금향의 휘발성 향기성분}

황금향의 휘발성 향기성분은 $\mathrm{SDE}$ 방법으로 추출하였으 며, 추출된 화합물은 $\mathrm{GC} / \mathrm{MS}$ 로 확인하여 화합물들의 상대 적 농도를 Table 1에 나타내었고, chromatogram은 Fig. 1에 도식하였다. 황금향에서 확인된 휘발성 화합물은 102 종으 로 함량은 $4,293.39 \mathrm{mg} / \mathrm{kg}$ 의 향기성분을 획득하였다. 황금 향의 휘발성 화합물은 관능기별로는 hydrocarbon류가 29종 으로 가장 많았으며, 그 다음으로는 alcohol류가 25종 aldehyde류 22종, ester류 13종, acid류 5종, ketone류 4종 및 oxide류 4종이 확인되었다. 관능기별 peak area는 hydrocarbon류가 $79.79 \%$ 로 가장 높았으며, aldehyde류 $7.88 \%$, alcohol류가 $6.18 \%$, ester류 $2.57 \%$, ketone류 $1.69 \%$, oxide류 $1.27 \%$ 및 acid류 $0.61 \%$ 순으로 나타났다. 황금향의 휘발성 향기성분 중 가장 높은 함량으로 확인된 화합물은 limonene으로 확인된 총 향기성분의 $50.21 \%$ 를 차지하였으 며, $2,155.68 \mathrm{mg} / \mathrm{kg}$ 이 함유되어 있었다. Limonene 이외에 $\beta$-myrcene $10.63 \%(456.27 \mathrm{mg} / \mathrm{kg})$, $\beta$-pinene $3.52 \%(150.99$ $\mathrm{mg} / \mathrm{kg})$, (E)- $\beta$-farnesene $3.09 \%(132.84 \mathrm{mg} / \mathrm{kg})$, a-pinene $3.04 \%(130.35 \mathrm{mg} / \mathrm{kg})$, valencene $2.81 \%(120.61 \mathrm{mg} / \mathrm{kg})$ 및 linalool $2.14 \%(92.01 \mathrm{mg} / \mathrm{kg})$ 등으로 확인되었다. 황금향의 휘발성 화합물 중 terpene류는 71종으로 전체 향기성분의 
$94.82 \%$ 를 차지하여 $4,070.95 \mathrm{mg} / \mathrm{kg}$ 의 함량을 나타내었다 (Table 3). Terpene류 중 monoterpene hydrocarbon류의 함량 이 높았으며, 그 다음으로 sesquiterpene hydrocarbon류의 함량이 많았다(Fig. 3). 황금향에서 확인된 monoterpene hydrocarbon류는 a-thujene, a-pinene, camphene, sabinene, $\beta$-pinene, $\beta$-myrcene, limonene, (E)- $\beta$-ocimene, $\gamma$-terpinene, a-terpinolene, $\rho$-cymenene 및 1,3,8-p-menthatriene 등이 분석 되었다. Sesquiterpene hydrocarbon류는 $\delta$-elemene, a -copaene, $\beta$-cubebene, a-funebrene, (E)- $\beta$-caryophyllene, $\gamma$ -elemene, (E)- $\beta$-farnesene, $\alpha$-humulene, $\gamma$-gurjunene, germacrene $\mathrm{D}$, selina-4,11-diene, valencene, bicyclogermacrene, (E,E)- $\mathrm{a}$ -farnesene, a-bulnesene, $\delta$-cadinene 및 $\beta$-sesqui phellandrene 등이 확인되었다. Oxygenated monoterpene류는 (Z)-linalool oxide, (Z)-sabinene hydrate, linalool, $\beta$-thujone, (E)-p-mentha2,8-dienol, (Z)-p-menth-2-en-1-ol, (E)-limonene oxide, citronellal, (E)-B-terpineol, 4-terpineol, a-terpineol, (E)-carveol, citronellol, (Z)-carveol, neral, carvone, geranial, perillaldehyde 및 limonen-10-ol 등이 확인되었다. Oxygenated sesquiterpene 류는 a-elemol, (E)-nerolidol, spathulenol, caryophyllene oxide, humulene epoxide II, $\gamma$-eudesmol, T-muurolol, T-cadinol, neo-intermedeol, intermedeol, $\beta$-sinensal, (E,Z)-2,6 -farnesal, (E,Z)-2,6-farnesol, (E,E)-farnesal, a-sinensal 및 nootkatone 등이 확인되었다. p-Cymenene, $\beta$-thujone, selina-4,11-diene 및 (E,E)-2,6-farnesol 은 제주 감귤류 중 황금향에만 함유되어 있었다.

\section{레드향의 휘발성 향기성분}

$\mathrm{SDE}$ 방법으로 레드향의 휘발성 향기성분을 분리하여 GC/MS로 확인하였다. 이들 화합물의 상대적 농도를 Table 1에 나타내었고, chromatogram은 Fig. 1에 도식하였다. 레드 향에서 확인된 휘발성 화합물은 108 종으로 함량은 $4,049.94$ $\mathrm{mg} / \mathrm{kg}$ 의 향기성분을 확인하였다. 레드향의 휘발성 화합물 은 관능기별로는 hydrocarbon류가 36종으로 가장 많았으 며, 그 다음으로는 alcohol류 26종, aldehyde류 24종, ester류 10 종, acid류 4종, ketone류 4종과 oxide류 4종이 확인되었 다. 관능기별 peak area는 hydrocarbon류가 $75.67 \%$ 로 가장 높았으며, aldehyde류 $13.20 \%$, alcohol류가 $8.57 \%$, acid류 $0.85 \%$, ester류 $0.66 \%$, oxide류 $0.64 \%$ 및 ketone류 $0.41 \%$ 순으로 나타났다. 레드향의 주요 휘발성 향기성분은 limonene 51.38\%(2,099.09 mg/kg), $\beta$-myrcene 7.23\%(292.61 $\mathrm{mg} / \mathrm{kg})$, linalool $4.81 \%(194.94 \mathrm{mg} / \mathrm{kg})$, decanal $4.32 \%(174.89$ $\mathrm{mg} / \mathrm{kg}$ ), a-pinene $4.23 \%(171.34 \mathrm{mg} / \mathrm{kg})$, a-sinensal $3.13 \%$ (126.93 mg/kg), $\beta$-pinene $2.48 \%(100.55 \mathrm{mg} / \mathrm{kg})$, citronellal $1.97 \%(79.68 \mathrm{mg} / \mathrm{kg})$, a-phellandrene $1.91 \%(77.27 \mathrm{mg} / \mathrm{kg})$, octanal $1.45 \%(58.70 \mathrm{mg} / \mathrm{kg})$ 및 a-thujene $1.23 \%(49.98$ $\mathrm{mg} / \mathrm{kg}$ ) 등 순으로 확인되었다. 레드향의 휘발성 향기성분 중 terpene류는 77 종으로 전체 향기성분의 $90.52 \%$ 를 차지
하였으며, 함량은 $3,665.62 \mathrm{mg} / \mathrm{kg}$ 으로 확인되었다(Table 3). Terpene류 중 monoterpene hydrocarbon류가 차지하는 비율 이 가장 높았으며, 그 다음으로 oxygenated monoterpene류 의 함량이 많았다(Fig. 3). 레드향에서 확인된 monoterpene hydrocarbon류는 limonene, a-thujene, a-pinene, camphene, sabinene, $\beta$-pinene, $\beta$-myrcene, a-phellandrene, $a$-terpinene, $\rho$-cymene, (E)- $\beta$-ocimene, $\gamma$-terpinene, $\alpha$-terpinolene, 1,3,8- $\rho$ -menthatriene 및 isophorone 등이 분석되었다.

Sesquiterpene hydrocarbon류는 bicycloelemene, $\delta$-elemene, $a$-cubebene, $a$-copaene, $\beta$-elemene, (E)- $\beta$-caryophyllene, $\gamma$ -elemene, $\alpha$-guaiene, $(\mathrm{E})-\beta$-farnesene, $\alpha$-humulene, $\gamma$-gurjunene, germacrene $D, \beta$-selinene, valencene, bicyclogermacrene, (E,E)-a-farnesene, $a$-bulnesene, $\gamma$-cadinene, $\delta$-cadinene 및 7-epi-a-selinene 등이 확인되었다. Oxygenated monoterpene 류 중 (Z)-sabinene hydrate, (E)-p-mentha-2,8-dienol, (Z)-pmenth-2-en-1-ol, (E)-limonene oxide, citronellal, (E)- $\beta$ -terpineol, $\rho$-cymen-8-ol, citronellol, (Z)-carveol, neral, carvone, geranial, perillaldehyde, bornyl acetate, limonen-10-ol 및 carvacrol 등이 확인되었다. Oxygenated sesquiterpene류는 a-elemol, (E)-nerolidol, spathulenol, caryophyllene oxide, viridiflorol, humulene epoxide II, $\gamma$-eudesmol, T-muurolol, T-cadinol, (E,Z)-2,6- farnesal, (Z,E)-a-bergamotol, (E,E)farnesal, oplopanone 및 $a$-sinensal 등이 확인되었다. $\rho$ -Cymen-8-ol, bornyl acetate, carvacrol, bicycloelemene, a -cubebene 및 7-epi-a-selinene은 제주 감귤류 중 레드향에서 만 확인된 향기성분이다.

\section{요 약}

제주감귤류(천혜향, 한라봉, 진지향, 황금향 및 레드향) 의 휘발성 향기성분을 분석하기 위하여 $\mathrm{SDE}$ 방법으로 휘발 성 화합물을 추출한 후 $\mathrm{GC} / \mathrm{MS}$ 로 확인하였다. 천혜향의 휘발성 향기성분은 104 종 $(4,939.77 \mathrm{mg} / \mathrm{kg})$, 한라봉 98 종 $(3,286.38 \mathrm{mg} / \mathrm{kg})$, 진지향 105 종 $(3,317.56 \mathrm{mg} / \mathrm{kg})$, 황금향 102 종 $(4,293.39 \mathrm{mg} / \mathrm{kg})$ 및 레드향 108 종 $(4,049.94 \mathrm{mg} / \mathrm{kg})$ 으 로 확인되었다. Limonene, sabinene, $\beta$-myrcene, $a$-pinene, $\beta$-pinene, linalool, 4-terpineol, a-terpineol, (E)- $\beta$-ocimene 및 $\gamma$-terpinene 등은 제주감귤류의 공통적인 주요 향기로 확인 되었다. Ethyl-benzene, nonanol, 1-p-menthen-9-al, (E)isocarveol, methyl salicylate, a-terpinen-7-al, perilla alcohol 및 ethyl dodecanoate은 천혜향에서만 확인된 휘발성 향기

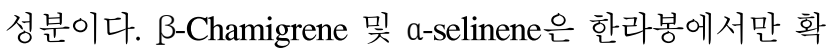
인되었으며, 3-hydroxybutanal, (E)-2-nonenal, isoborneol, octyl acetate, (E)-2-undecenal, $\beta$-ylangene 및 guaia-6,9-diene 은 진지향에서만 확인되었다. $\rho$-Cymenene, $\beta$-thujone, selina-4,11-diene 및 (E,E)-2,6- farnesol은 황금향에서만 확 
인되었으며, $\rho$-cymen-8-ol, bornyl acetate, carvacrol, bicyclo elemene, a-cubebene 및 7-epi-a-selinene 등은 레드향에서만 확인된 향기성분이다. Limonene은 제주감귤류의 휘발성 향기성분 중 가장 많은 함량으로 확인되었으며, 비율은 42.57\% 62.18\%이다. 본 연구결과 제주감귤류의 품종에 따 른 휘발성 향기성분 함량과 조성의 차이를 확인할 수 있었다.

\section{감사의 글}

이 논문은 2016년 한국연구재단 지역대학 우수과학자 지원사업(2016RIDIA3B03934419)에 의하여 연구되었으 며, 이에 깊이 감사드립니다.

\section{References}

1. Kaneko K, Katayama O (1980) Studies on volatiles from satsuma mandarin juice 1 . difference of volatile components among each part of mandarin citrus unshiu cultivar satsuma fruit. National Food Research Institute, 36, 44-50

2. Shimoda M, Osajima Y (1981) Studies on off-flavour formed during storage of satsuma mandarin juice. Japan J Agric Chem Soc, 55, 319-324

3. Moon KH, Song EY, Son IC, Oh SJ, Park KS, Hyun HN (2015) Quantification of environmental characteristics on citrus production area of jeju island in Korea. Korean J Agric For Meteorol, 17, 69-74

4. Lee SG, Jeon SG (2016) An analysis on the change of the management efficiency distribution of citrus farms. J Agric Life Sci, 50, 207-221

5. Song $\mathrm{Ej}$ (2014) A study on production system of hallabong on jeju island. MS Thesis, Chung-Buk University, Korea, p 43-50

6. Berger RG (2006) Flavours and fragrances, Chemistry, Bioprocessing and Sus tainability. Springer Science \& Business Media, 117-119

7. Fahlbusch KG, Hammerschmidt FJ, Panten J, Pickenhagen W, Schatkowski D, Bauer K, Garbe D, Surburg H (2003) Flavors and fragrances. Ullmann's Encyclopedia of Industrial Chemistry, 103

8. Plotto A, Margaríia CA, Goodner KL, Baldwin EA (2008) Odour and flavour thresholds for key aroma components in an orange juice matrix: esters and miscellaneous compounds. Flav Frag J, 23, 398-406

9. Ohta H, Yoshida K, Hyakudome K, Aoyagi H, Okabe
M, Susukida W (1983) Effects of headspace, pasteurization condition and storage temperature on quality of canned satsuma mandarin juice during storage. Nippon Shokuhin Kogyo Gakkaishi, 30, 200-208

10. Araki C, Sakakibara H (1991) Changes in the volatile flavor compounds by heating satsuma mandarin(citrus unsbiu marcov.) juice. Agric Biol Chem, 55, 1421-1423

11. Moshonas MG, Shaw PE (1996) Volatile components of calamondin peel oil. J Agric Food Chem, 44, 1105-1107

12. Wilson CW, Shaw PE (1981) Analysis of cold-pressed grapefruit oil by glass capillary gas chromatography. J Agric Food Chem, 29, 494-496

13. Schultz TH, Flath RA, Mon TR, Eggling SB, Teranishi $\mathrm{R}$ (1977) Isolation of volatile components from a model system. J Agric Food Chem, 25, 446-449

14. Nickerson GB, Likens ST (1996) Gas chromatography evidence for the occurrence of hop oil components in beer. J Chromatogr A, 21, 1-5

15. Seo HY, No KM, Shim SL, Ryu KY, Han KJ, Gyawali R, Kim KS (2006) Analysis of enantiomeric composition of chiral flavor components from dried ginger (Zingiber officinale roscoe). J Korean Soc Food Sci Nutr, 35, 874-880

16. Schreier P (1986) Biogeneration of Plant Aromas. In: Developments in Food Flavours, Birch GG, Lindley MG (Editor) Elsevier Applied Science, London \& New York, p 89-106

17. Furuta $T$, Yoshii $H$, Kobayashi $T$, Nishitarumi $T$, Yasunishi A (1994) Powdery encapsulation of d-limonene by kneading time with mixed powders of $\beta$-cyclodextrin at low water content. Biosci Biotechnol Biochem. 58, 847-850

18. Sadtler Research Laboratories (1986) The sadtler standard gas chromatography retention index library. Sadtler, USA

19. Langer RS, Wise DL (1984) Medical applications of controlled release. CRC Press. Florida, USA, p 2-12

20. Rosen HB, Chang J, Wnek GE, Linhardt RJ, Langer R (1983) Bioerodible polyanhydrides for controlled drug delivery. Biomaterials, 4, 131-133

21. Kang MA (2012) Analysis of free sugars, organic acids and flavonoids in shiranuhi and setoka citrus fruits, and bioactivity of essential oil. MS Thesis, Jeju National University, Korea, p 29-31

22. Song HS, Sawamura M, Ito T, Ido A, Ukeda H (2000) Quantitative determination and characteristic flavour of daidai (Citrus aurantium L. var. Cyathifera Y. Tanaka) 
peel oil. Flavour Fragr, 5, 323-328

23. Akahoshi G (1983) Kouryonokagaku (in Japanese), Dainihontosyo. Tokyo, Japan, p 148-315

24. Chen J, Duan W, Bai R, Yao H, Shang J, Xu J (2014) Design, synthesis and antioxidant activity evaluation of novel beta-elemene derivatives. Bioorg Med Chem Lett, 24, 3407-3411

25. Li X, Wang G, Zhao J, Ding H, Cunningham C, Chen F, Flynn DC, Reed E, Li QQ (2005) Antiproliferative effect of beta-elemene in chemoresistant ovarian carcinoma cells is mediated through arrest of the cell cycle at the G2-M phase. Cell Mol Life Sci, 62, 894-904

26. Calcabrini A, Stringaro A, Toccacieli L, Meschini S, Marra M, Colone M, Salvatore G, Mondello F, Aracia G, Molinari A (2004) Terpinen-4-ol, the main component of melaleuca alternifolia (tea tree) oil inhibits the in vitro growth of human melanoma cells. J Invest Dermatol, $122,349-360$
27. Hart PH, Brand C, Carson CF, Riley TV, Prager RH, Finlay-Jones JJ (2000) Terpinen-4-ol, the main component of the essential oil of melaleuca alternifolia (tea tree oil), suppresses inflammatory mediator production by activated human monocytes. Inflamm Res, 49, 619-626

28. Carson CF, Riley TV (1995) Antimicrobial activity of the major components of the essential oil of melaluca alternifolia. J Appl Bacteriol, 78, 264-269

29. Yoo ZW (2003) Comparative analyses of the flavors from Hallabong (Citrus sph aerocarpa) with lemon, orange and grapefruit by SPTE and HS-SPME combined with GC-MS. Ph D Thesis, Seoul Women's University, Korea, p 9-29

30. Choi SH (2008) Volatile aroma components of hibiscus herb tea. J Kor Tea Soc, 14, 195-204 